\title{
Research Report on the Protection of Drinking Water Sources in Kite Rock Reservoir
}

\author{
Ping Dong ${ }^{1, a}$, Xin Xiang ${ }^{2, b}$ and Limin Dong ${ }^{3, c^{*}}$ \\ ${ }^{1}$ Instituteof Geography and oceanography, Nanjing University,Nanjing, Jiangsu, China \\ ${ }^{2}$ Instituteof Economics and business administration, Central China Normal University,Wuhan, Hubei, \\ China \\ ${ }^{3}$ Instituteof Economics and business administration, Central China Normal University,Wuhan, Hubei, \\ China \\ a2246453962@qq.com, b2545937385@qq.com, dlm6805@126.com
}

Keywords: Reservoir; Drinking water sources; Protection; Investigation; Project

Abstract. The protection of drinking water sources is an important part of water pollution control and management in China. Drinking water sources is not only an important source of water for residents, but also plays an irreplaceable role in agricultural irrigation, flood control, power generation, aquaculture and so on. However, due to the expansion of people's production and living activities and the lack of awareness of environmental protection, many areas of our country have been polluted to different degrees, which seriously affects the safety of people's drinking water and the quality of ecological environment. Therefore, the effective treatment and scientific protection of drinking water sources is a serious problem to be solved. Taking the research and management of Kite rock reservoir drinking water sources in Qichun as an example and interviewing and investigating County Water Conservancy Bureau, Aquatic Products Bureau and State Marine Board in Qichun, the author conducted a thematic research about the water operation and management of kite rock reservoir and made a number of recommendations on protection of drinking water sources in the reservoir. Suggestions put forward include: 1) The operation rights of aquaculture in the reservoir should be reclaimed according to the law. Ecological aquaculture, density control and pollution reduction need to be eagerly promoted in order to realize the reservoir's natural development, scientific breeding and reasonable fishing. Events that disrupt the balance of alga in the reservoir should be strictly prohibited; 2) Impose a ban on ferries to resolve the major potential hazard for water pollution in the reservoir a step further; 3) Prohibit reservoir tourism and leisure activities to prevent the pollution caused by relevant activities.

\section{The Water Operation and Current Management of Kite Reservoir}

Kite rock reservoir in Qichun County, Hubei Province, is the only first level water conservation reservoir, and it is a main medium sized reservoir mainly for flood control, irrigation and urban water supply, taking into account the comprehensive utilization of power generation and aquaculture. Water management and activities are mainly in the following three situations:

Water aquaculture. The aquaculture area in Kite rock reservoir is 1200 acres (normal average), The aquaculture area above 24 meters from the water level is up to 2000 acres. Since the Sesame mountain was built in 1992 and provided water for the tap water company in Xiang County, the surface of the reservoir has been developing naturally, prohibiting all the manufacturing activities which affect the quality of water, it includes a ban on fertilizer spray, bait fish and so on. The water surface has been transferred to $\mathrm{Mr} \mathrm{Yu}$, a staff in the department of management of reservoir to raise fishes (divided into three time periods: from 1997 to 2002, and turned over management fees of 355,000; from 2002 to 2007, and turned over management fees of 360,000 yuan; in 2007-2017, turned over management fees of 820,000 yuan. All the fees were paid off at one time when the contract was signed), and four staffs are employed. Breeding fish fry is mainly variegated carp and silver carp, the normal annual production of fish is around 120,000, purchasing matured fish to raise is 200,000 to 300,000 pounds, the total output reached 300,000 to 420,000 pounds. The matured fish 
for raising are bought elsewhere from October to December when the price is the lowest, and are put into the reservoir to breed. At May next years the fish are sold at high price in order to reap the profits.

Ferry operations. There are four paddle ferries in Machong ferry of kite rock reservoir. In 2010, county government instructed State Marine Board in Qizhou to reconstruct the ferries in order to prevent pollution of drinking water. State Marine Board got rid of four ferries which are heavliy polluted and high energy consumed and encouraged Mr Ma(a staff managing the ferry) to purchase two new cockpit models ferries, based on the principles of convenient travel for people, improved security situation of ferries and prevention of drinking water pollution for residents, combining national policy that benefits farmers on " subsidies to reconstruct rural ferries". Because the road in Machong village was completed, the capacity of ferries has fallen year by year, the capacity is below 10 people per day now. Everyone was charged two yuan, mainly the elderly, children and tourists. Two ferries received a total of 14000 yuan fuel subsidies per year from State Maritime Bureau to maintain operation .

Tourism and leisure. Kite rock is a rare natural scenery near the town which is three kilometers away from the county. In recent years, due to the rise of outdoor sports, there is an increasing number of people going fishing, swimming and picnic. According to incomplete statistics, there are over 100 people swimming in the reservoir during the high temperature from June to September in recent years. In addition, more than 100 people go fishing around the reservoir during open period from October to May next year.

\section{The Pollution of Water Operation}

The water pollution is not only derived from external pollution, it has the following three aspects:

Aquaculture on water pollution. After the contracted aquaculture of the reservoir, the species of fish is single, which is mainly variegated carp and silver carp, do not meet the principles of diversity; besides, the number of breeding fish is beyond as four times as water sources conservation which is naturally raised, resulting in incomplete biologic chain, overlay of fish waste and other pollutants. It also destroys the balance of algae, water cannot achieve a virtuous circle, its self-purification ability is deteriorated or weakened and the water quality is declining. People doubted whether investing fertilizer fish, so we conducted local research, no evidence was found, however.

Ferries operation on water pollution. There are two ferries are cockpit type, in addition to the air pollution caused by existing host emissions, the release of the circulating cooling water, the failure of the tail shaft lubrication system, the leakage of the main engine fuel and bilge oily water will be the major potential hazard for water pollution in the reservoir.

Travel and leisure on water pollution. There are a number of people taking a trip, having a picnic and going fishing perennially in the conservation zones of the reservoir, creating plenty of white pollutions which have a bad impact on the quality of water. Especially during the megathermal period in summer each year, more than 100 people are swimming in Machong ferry and near the dam, which have a great influence on water quality. Although authorities have tried to thwart and persuade, but the effect is not obvious. In addition, the reservoir's contractor open the reservoir to the public from October to May each year and charge 30 yuan per person per day. The number of people can up to more than 100 a day. Obviously, the baits and drugs have an impact on water quality.

\section{Suggestion}

According to water pollution generated from water operation and activities in kite rock reservoir, it is recommended that:

The operation rights of aquaculture should be reclaimed according to the law. In order to enhance the credibility of the government and resolve contradictions between pisciculture and water supply, it is adviced that the operation rights of aquaculture needs to be recovered and the reservoir is in charge of ecological aquaculture, density control and pollution reduction to realize its natural development, scientific breeding and reasonable fishing. Events that disrupt the balance of alga in the reservoir should be prohibited and extensive measures need to be taken to keep the balance. 
Impose a ban on ferries. Currently, the roads in Machong, Liju and other villages have been finished, the local network has formed and the "village village pass" project has started. The load factor of the two ferries in reservoir remains low, less than 10 people a day and are mainly tourists. Therefore, it is recommended that Airlines Bureau in Qizhou should take back the operation rights of the two ferries. The reservoir water managers are supposed to purchase a more environmental motor ferry to manage the water in reservoir and prevent floods.

Prohibition of reservoir tourism and leisure activities. With regard to harmful activities such as fishing, swimming and having a picnic in reservoir, TV, broadcast, Internet and other media should be made full use to give great publicity. Further, anouncements should be posted in the villages near reservoir and along the main roads to reservoir to draw attention. In addition, it is recommended that the Public Security Bureau lead and organize Environmental Protection Bureau and Water Conservation Bureau to carry out joint law enforcement, exposing people who are not obeying the rules.

\section{Acknowledgements}

Corresponding author: Limin Dong (dlm6805@126.com)

\section{References}

[1] Qiulian Wang, Zhen Zhang, Wei Liu. Drinking water environmental health risk assessment in Tianjin[J]. Environmental science and technology. 05(2000) 187-190. ( in Chinese )

[2] Tao He . Control measures of the rural non-point source pollution in drinking water sources in Sanming[J]. Sanming University. 02(2009) 218-221. ( in Chinese )

[3] Chen Chen, Lingli Xie, Xiangdong Yan, Yongwen Huang. Problems and countermeasures of protection of drinking water sources in Yichang[J]. Environmental science and management. 08(2009) 14-17. ( in Chinese )

[4] Wenjin Zhang, Deshan Tang. Drinking water source protection and management research in China[J]. People of the Yellow River. 08(2009) 55-56. ( in Chinese )

[5] Fen Zhou, Xiaoyan Lu. Study on safety and security measures of the reservoir drinking water source area in Zhejiang Province[J]. Chinese rural water conservancy and hydropower. 08(2009) 37-40. ( in Chinese )

[6] Lihong Wang, Kaizhang Wang, Fengfan Liu, Fanliang Kong. Connotation, status quo and countermeasures of safety of drinking water source area[J]. Shandong agricultural science. 05(2007) pp. 94-96+100. ( in Chinese )

[7] Rile Ge. Drinking water source protection in China and legislative proposals[J]. Resources and industrial. 01(2008) 80-82. ( in Chinese )

[8] Hongwei Liu, Wen Yi, Wutao Zeng, Kangsai Zhao. Environmental protection of drinking water sources in Guangdong province to explore[J]. Environment and sustainable development. 03(2008) 56-58. ( in Chinese )

[9] Fengcun Yu, Guohua Fang, Study on construction of comprehensive early-warning index system of drinking water sources[J]. Chinese rural water conservancy and hydropower. 08(2011) 93-95+99. ( in Chinese )

[10] Hua Hu, Guojun Zhang, Guo Zhang, Lin Hong. Actuality and suggestion of drinking water 
source protection in Kaifeng[J]. Chinese rural water conservancy and hydropower. 10(2006) 59-60. ( in Chinese )

[11] Yuqin Chen, Junfang Li. Study on prevention and control of drinking water sources and early warning system[J]. Environmental monitoring and early warning. 06(2013) 49-51. ( in Chinese )

[12] Lijuan Yang. Rural drinking water quality and environmental protection in Lincang[J]. Environmental science guide. 06(2012) 52-54. ( in Chinese )

[13] Lingzhi Hu, Aiping Zhang, Min Wang. Study on the protection of drinking water sources in Chengdu[J]. People in the Yangtze River. 12(2014) 16-18+26. ( in Chinese ) 